\title{
Changes in Surface Wind Speed over North America from CMIP5 Model Projections and Implications for Wind Energy
}

\author{
Sujay Kulkarni and Huei-Ping Huang \\ School for Engineering of Matter, Transport, and Energy, Arizona State University, Tempe, AZ 85281, USA \\ Correspondence should be addressed to Sujay Kulkarni; sskulka8@asu.edu
}

Received 14 March 2014; Accepted 12 August 2014; Published 1 September 2014

Academic Editor: Taewoo Lee

Copyright ( 2014 S. Kulkarni and H.-P. Huang. This is an open access article distributed under the Creative Commons Attribution License, which permits unrestricted use, distribution, and reproduction in any medium, provided the original work is properly cited.

The centennial trends in the surface wind speed over North America are deduced from global climate model simulations in the Climate Model Intercomparison Project—Phase 5 (CMIP5) archive. Using the 21st century simulations under the RCP 8.5 scenario of greenhouse gas emissions, 5-10 percent increases per century in the $10 \mathrm{~m}$ wind speed are found over Central and East-Central United States, the Californian Coast, and the South and East Coasts of the USA in winter. In summer, climate models projected decreases in the wind speed ranging from 5 to 10 percent per century over the same coastal regions. These projected changes in the surface wind speed are moderate and imply that the current estimate of wind power potential for North America based on present-day climatology will not be significantly changed by the greenhouse gas forcing in the coming decades.

\section{Introduction}

The rapid technological developments in the past decade have established wind energy as one of the major alternatives to fossil-fuel based energy. The potential of wind power generation in the United States alone, including off-shore and on-shore capacity, is estimated to be about $15000 \mathrm{GW}$ (e.g., Lopez et al. [1]). This estimate generally does not take into account future climate changes which may alter the pattern and strength of near-surface wind at desirable locations for wind farms (Freedman et al. [2], Ren [3]). Worldwide, longterm projections of decadal-to-centennial climate changes due to anthropogenic emission of greenhouse gases (GHG) have been systematically carried out by climate modeling groups that participate in the Climate Model Intercomparison Project-Phase 5 (CMIP5, Taylor et al. [4], cmip5pcmdi.llnl.gov/cmip5), in close association with the Intergovernmental Panel on Climate Change (IPCC) of the United Nations (IPCC [5]). While climate model outputs from CMIP5 and its predecessors have been widely used to project regional changes in temperature and hydrological cycles (e.g., Seager et al. [6], Baker and Huang [7]), few studies have used the datasets to project future changes in surface wind. Notably, Pryor and Barthelmie [8] analyzed the regional model simulations in NARCAAP (Mearns et al. [9]), constrained by the global model projections from CMIP3 (Meehl et al. [10]), to conclude that GHG-induced climate change will not significantly affect wind power potential in the United States in the coming decades. As a contribution to this underexplored area of research, this study will use a subset of the newer CMIP5 model data to construct the GHG-induced trends in the near-surface wind speed over North America.

The horizontal resolution of the global climate models in CMIP5 is typically around $100-150 \mathrm{~km}$ in midlatitudes. It is understood that this is not fine enough to resolve detailed topography in the mesoscale and submesoscale, which can have nontrivial influences on the low-level wind field. Nevertheless, the information from the global models provide the first-order picture of the changes in the large-scale flow, which will form the basis for future efforts to downscale the global model output to regional and urban scales. The CMIP5 simulations for the 21st Century are driven by the radiative forcing deduced from different scenarios of anthropogenic emissions of GHG and industrial aerosols. Regional climate changes due to land-use changes (e.g., urbanization) or even the influence of large-scale wind farms (e.g., Keith et al. [11] and Adams and Keith [12]) are not covered by the 21st century scenarios in CMIP5 and are not considered in this work. 
TABLE 1: List of the CMIP5 models used in this study.

\begin{tabular}{llc}
\hline Model & Institution & Resolution \\
\hline EC-Earth & EC-Earth consortium (multiple) & $320 \times 160 /$ T159 (L62) \\
IPSL-CM5-LR & Institut Pierre-Simon Laplace (France) & $96 \times 96($ L39) \\
GISS-E2-H & NASA Goddard Institute for Space Studies (USA) & $144 \times 90($ L40) \\
CSIRO-MK 3.6.0 & Commonwealth Scientific and Industrial Research Organisation (CSIRO) and Queensland & $192 \times 96 /$ T63 (L31) \\
& Climate Change Centre of Excellence (Australia) & $192 \times 145($ L38) \\
\hline
\end{tabular}

\section{Datasets}

Five models, from CMIP5, EC-Earth, IPSL-CM5-LR, GISSE2-H, CSIRO-MK 3.6.0, and ACCESS 1.0 (listed in Table 1), are used in this study. By first examining the scatter plots of the indices of large-scale wind fields (in the manner of Paek and Huang [13]) over the Pacific-North American sector, the five models were selected as a subset that at least reflects the diversity (in terms of model resolution and biases) of the over 30 models in CMIP5. For example, IPSL-CM5-LR and GISS-E2-H substantially underestimate and CSIRO-MK 3.6.0 overestimates the Low Level Jet over North America, while the other two models produce only small biases in that feature (not shown). For our purpose of deducing trends, the historical runs for the 20th Century and the corresponding 21 st century runs under the representative concentration pathways (RCP) 8.5 scenario are used. As a brief background, the RCP8.5 scenario imposes $8.5 \mathrm{~W} / \mathrm{m}^{2}$ of radiative forcing, induced by the projected increase in GHG concentration, to the atmosphere towards the end of the 21st Century. It produces an increase in global mean surface air temperature which ranges from +2.6 to $+4.8^{\circ} \mathrm{C}$ over the 21 st Century from the projections by the majority of CMIP5 models (IPCC [5]).

The global models in CMIP5 typically have very few vertical levels within the planetary boundary layer. Given that wind turbines are usually at $80-100 \mathrm{~m}$ height, at which there is no direct model output, the closest standard output variables that we can use from CMIP5 are the surface wind speed and the vector wind field at $10 \mathrm{~m}$ height as calculated from boundary layer parameterization schemes. We will use the standard monthly mean archives of those variables from CMIP5. It is worth noting that, consistent with our purpose, the monthly mean of surface wind speed in the archive is the monthly average of the wind speed calculated at daily or subdaily frequency. While the wind speed at $10 \mathrm{~m}$ is generally less than that at 80-100 $\mathrm{m}$ height, the two are highly correlated and can be related by the Hellman exponent and wind gradient equation used for wind turbines (e.g., Kaltschmitt et al. [14]). Thus, we analyze the $10 \mathrm{~m}$ wind as a close proxy of the actual wind at the turbine height.

The simulations from the last two decades of the historical and RCP8.5 runs are used to deduce the trends. More precisely, the centennial trend is defined as the climatology of 2079-2099 minus the climatology of 1979-1999. Winter and summer will be analyzed separately. The $10 \mathrm{~m}$ wind data from the NCEP-DOE reanalysis-2 (Kanamitsu et al. [15], data obtained from the archive at http://www.esrl.noaa.gov/psd/) for 1979-1999 will also be used to cross validate the CMIP5 historical runs.

\section{Surface Wind Speed in Present and Future Climate}

Figure 1 shows the climatology of the surface $(10 \mathrm{~m})$ wind speed over North America for the winter season (DecemberFebruary) constructed from the last two decades of the 20th century historical runs (Figure 1(a)) and the last two decades of the 21st century RCP 8.5 runs (Figure 1(b)) using five different models in CMIP5. Figure 2 is similar to Figure 1 but for summer (June-August). For the 20th century simulations, the models produce the common first-order features with the highest wind speed over the oceans and relatively higher wind speed over the Great Plains compared to the Rockies and the Southeastern USA. The wind speed is higher in winter than in summer overall. These first-order features are also produced by the 21st century runs, giving the first indication that the GHG-induced climate change does not dramatically alter the surface wind field. Within either group of the 20th or 21st century runs, notable differences exist among the models. For example, in winter, GISS-E2-H and ACCESS 1.0 produce considerably stronger surface wind off the East Coast of the USA than other models; IPSL-CM5-LR and ECEarth produce a more distinctive local maximum of surface wind over North-Central USA which is less visible in the simulations by the other three models. It is also interesting to note that only EC-Earth produces local surface wind maximum over the Great Lakes. This is because the model has the highest resolution among the five (see Table 1), high enough to partially resolve the lakes. The fine structures mentioned above that are unique to an individual model tend to exist in both the 20th and 21st century simulations by that model. This indicates that the model bias remains similar under the GHG forcing in the 21st century. In other words, if one defines the trend as the difference between the 21st century climatology and 20th century climatology, both from the same model, the bias would cancel itself. Thus, the trend so deduced can still be meaningful even if the model has biases.

Figure 3 shows the trends in the surface wind speed, defined as the 2079-2099 climatology minus the 1979-1999 climatology, over North America for winter (Figure 3(a)) and summer (Figure 3(b)), based on the simulations by the five models shown in Figures 1 and 2. The models produce 

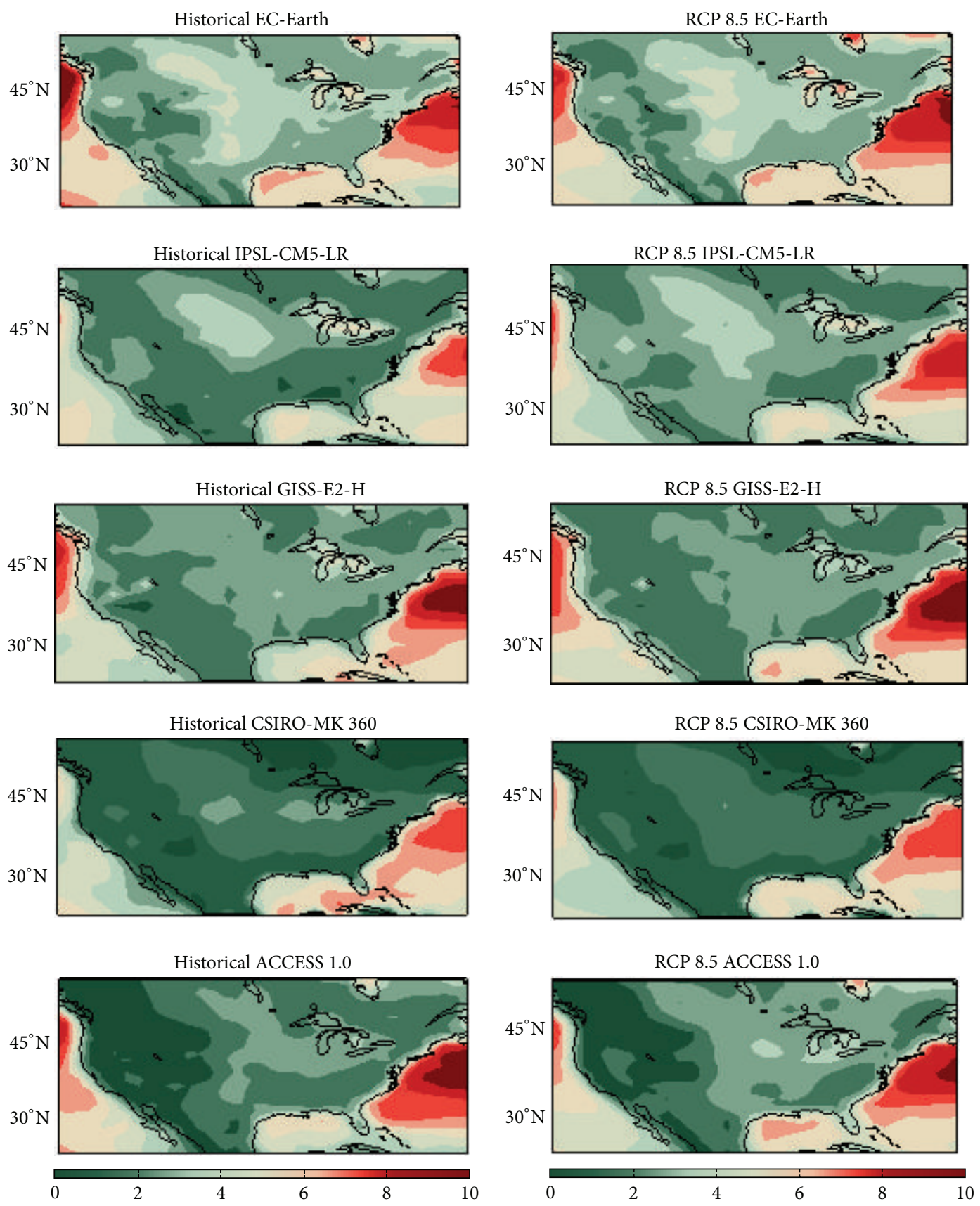

(a)

(b)

Figure 1: The climatology of surface wind speed over North America for winter (DJF) from the 20th century historical runs (a) and 21st century RCP 8.5 runs using five CMIP5 models as labeled at the top of each panel. The color scale, in m/s, is shown at bottom. Green and red colors represent lower and higher wind speed.

diverse responses to GHG forcing. For example, IPSL-CM5LR produces a positive trend in winter and negative trend in summer over almost the entire North American sector, while the responses in the CSIRO-MK 3.6.0 model are muted for both seasons. Nevertheless, when averaged across the models, the GHG-induced trends in the surface wind speed are overall an increase in winter and a decrease in summer over the North American continent. The increase in the surface wind speed in winter is broadly consistent with the enhancement of the eastward tropospheric jet stream aloft (which is a main feature in winter) found in previous analyses of the CMIP5 zonal wind data (Paek and Huang [13]).

The determination of the trends in Figure 3 is entirely based on models. As noted, if the model bias is not significantly affected by the GHG forcing in the 21st century, by taking the difference between the 21st and 20th century runs, 


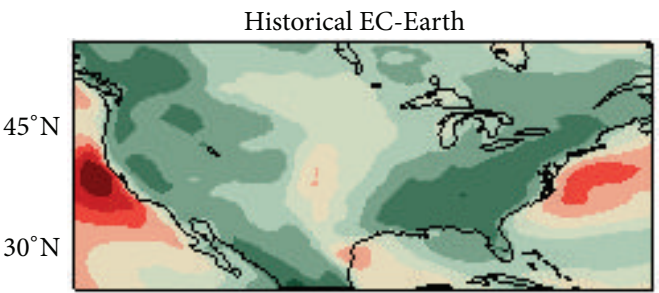

Historical IPSL-CM5-LR

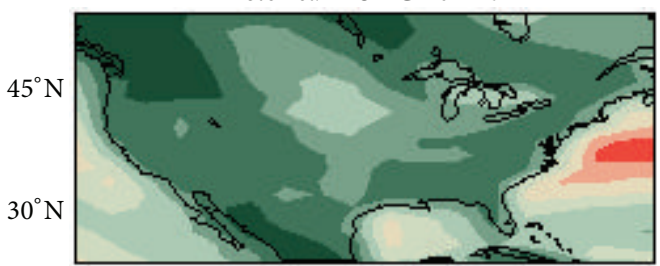

Historical GISS-E2-H

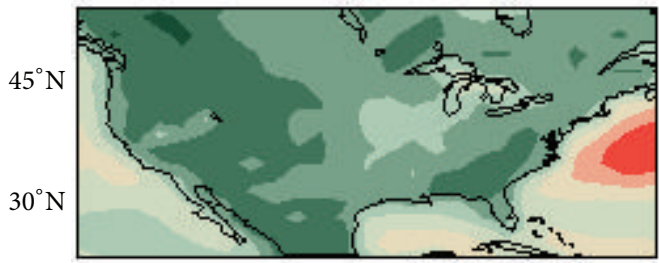

Historical CSIRO-MK 360
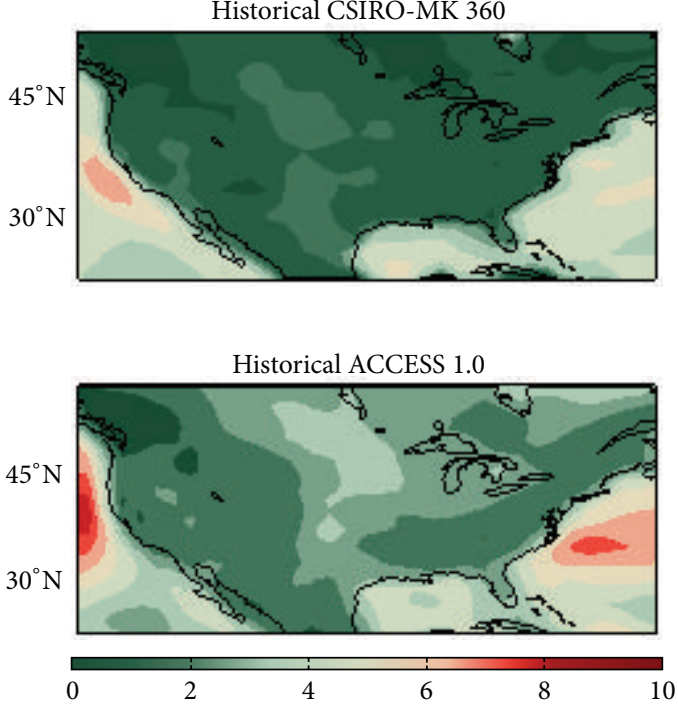

(a)

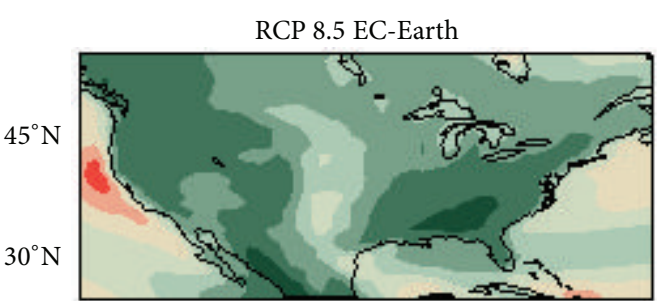

RCP 8.5 IPSL-CM5-LR

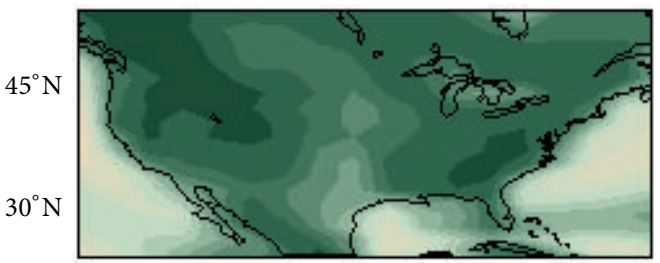

RCP 8.5 GISS-E2-H

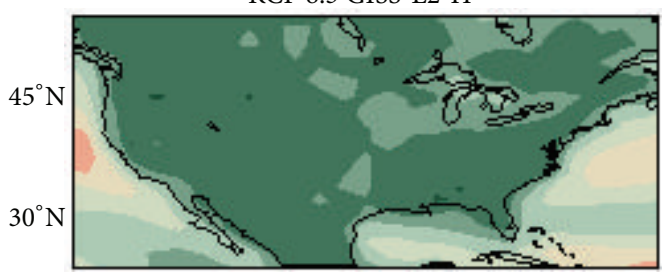

RCP 8.5 CSIRO-MK 360
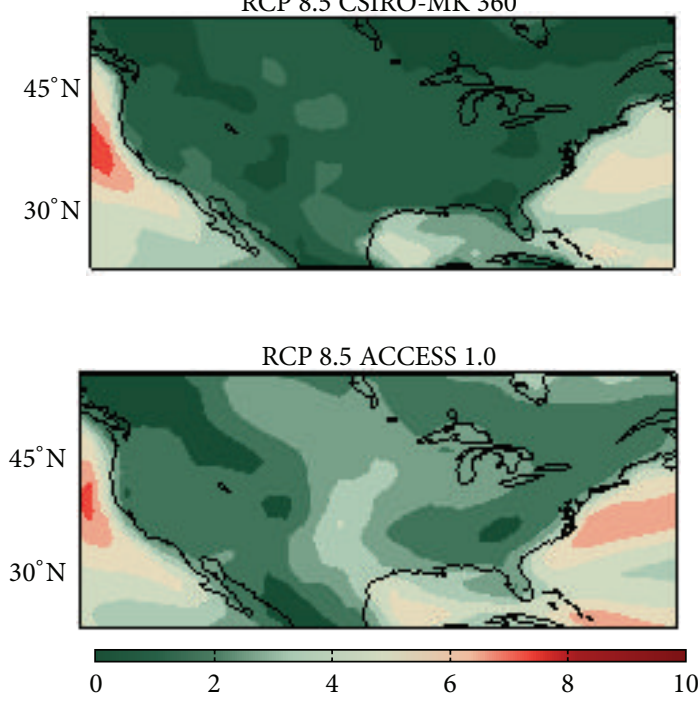

(b)

FIgURE 2: Similar to Figure 1 but for the climatology for summer (JJA). (a) and (b) are the historical and RCP 8.5 runs.

the bias would cancel itself. This philosophy is also adopted by the IPCC in its assessment reports on future climate (IPCC [5]). Nevertheless, for completeness, we should compare selected models with the 20th century reanalysis to affirm that the biases are not excessive. Figure 4 shows the 1979-1999 climatology (averaged over all seasons) of the surface wind speed from NCEP-DOE reanalysis-2 (Figure 4(a)), along with its counterparts from the historical runs using GISSE2-H (Figure 4(b)) and EC-Earth (Figure 4(c)). The overall patterns in reanalysis and model simulations are similar, although GISS-E2-H slightly underestimates the wind speed over West-Central US while EC-Earth overestimates it. A more complicated picture emerges if one further compares the climatology of the $u$ - and $v$-components of the 10 meter wind. Figure 5(a) is similar to Figure 4 but for the $v$-component of surface wind and Figure 5(b) is for the $u$ component of it. Although EC-Earth has a larger bias in the surface wind speed, it simulates the $v$-component of the wind field better than GISS-E2-H. The bias in EC-Earth is mainly in the $u$-component. The two cases in Figures 4 and 5 suffice to illustrate that the model biases have somewhat complicated patterns but are not excessive in their magnitude. Also, 

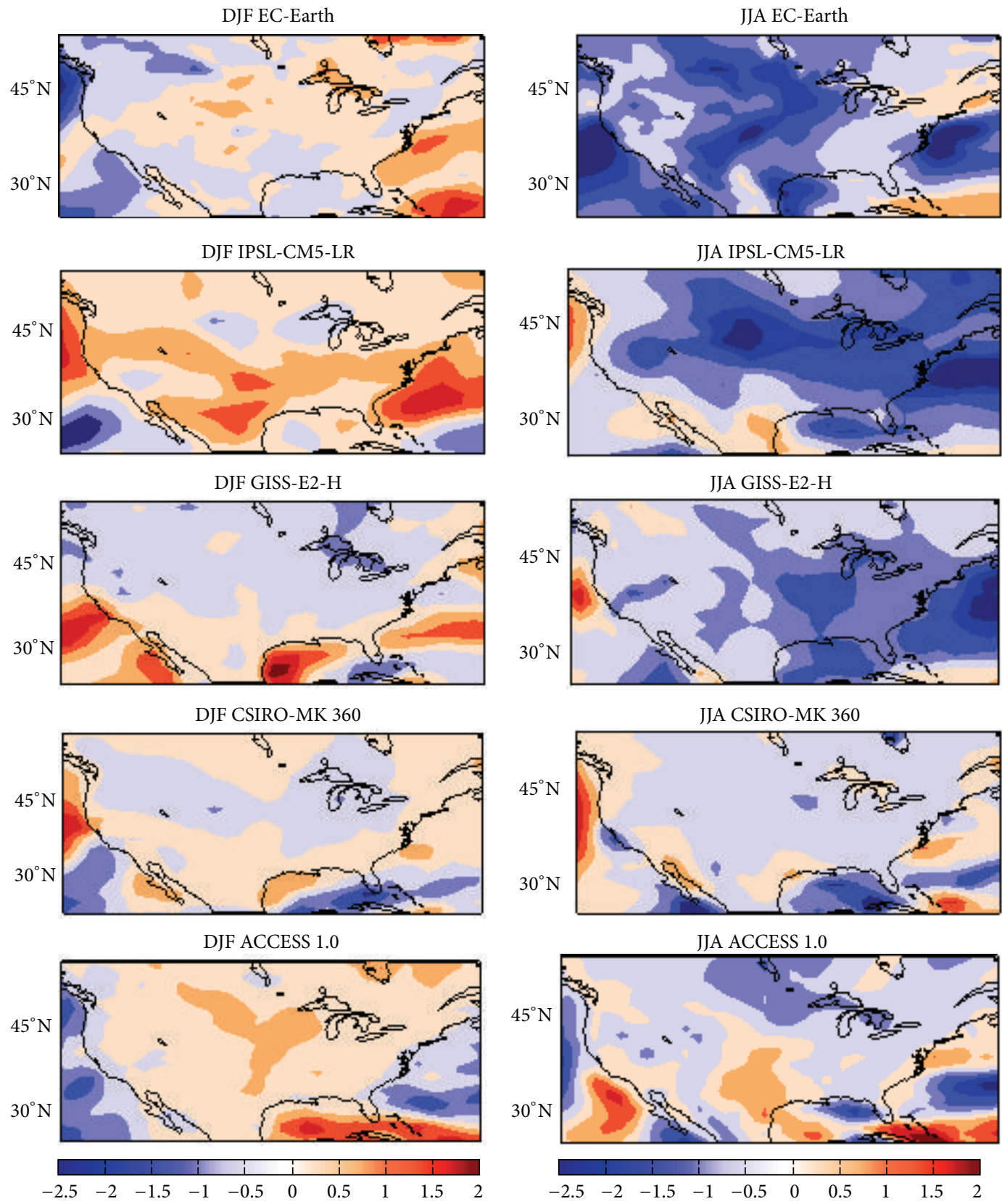

(a)

(b)

Figure 3: The trend [(2079-99) minus (1979-99)] in the surface wind speed over North America for winter (a) and summer (b), from five CMIP5 models as labeled at the top of each panel. The color scale, in $\mathrm{m} / \mathrm{s}$ (per century), is shown at bottom. Blue and red indicate a decrease and an increase, respectively, in the surface wind speed.

a further examination did not reveal a simple correspondence between the pattern of the bias and the pattern of the trend.

\section{Regional Surface Wind Fields}

With the changes in the surface wind speed shown in Figure 3, one may ask if there are also changes in the wind direction. The maps of the 10-meter wind fields, for selected models and regions with notable changes in wind speed, are shown in Figures 6 and 7. Figures 6(a) and 7(a) show the historical run and Figures 6(b) and 7(b) show the corresponding RCP 8.5 run. Wind fields are shown as the arrows, with the magnitude of the wind vector imposed in the background as the color shading. Figure 6 shows the ECEarth simulations for Central USA (top) and the East Coast of the USA (bottom) for summer. Figure 7 shows the GISSE2-H simulations for the Southern USA and part of Gulf of Mexico (top) and West Coast of the USA (bottom), both for 


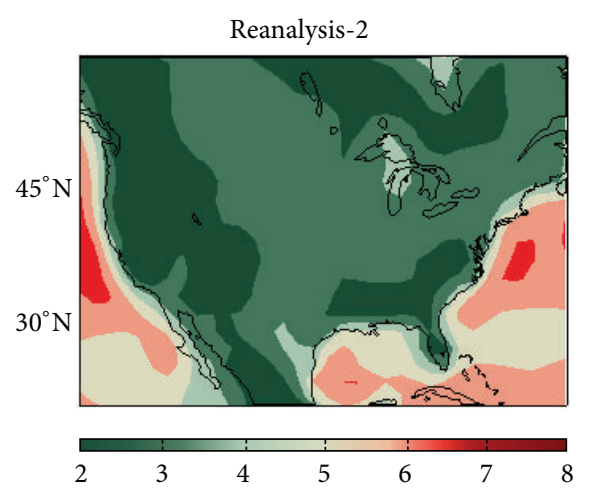

(a)

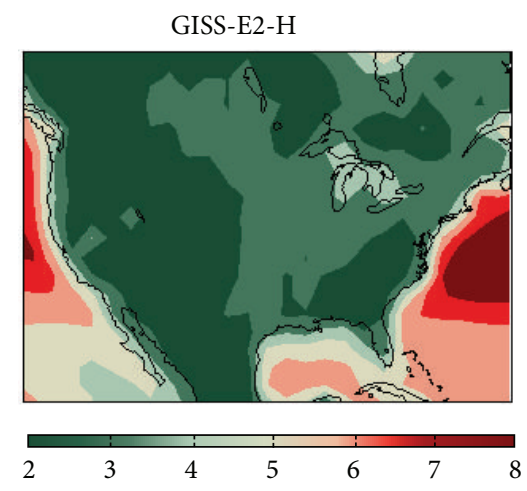

(b)

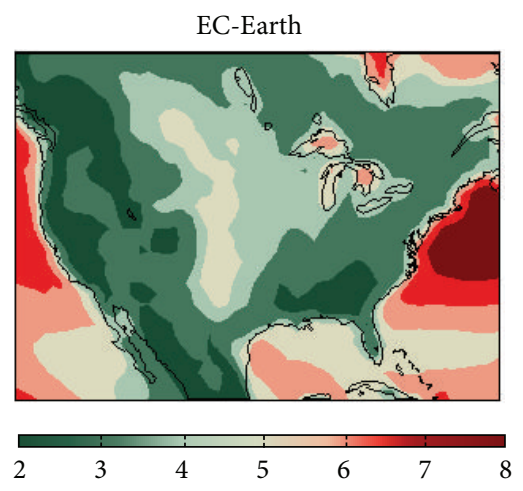

(c)

FIGURE 4: A comparison of the 1979-1999 climatology of the surface wind speed from NCEP-DOE reanalysis-2 (a) and the historical runs with two models (b) GISS-E2-H and (c) EC-Earth in CMIP5. The color scale, in m/s, is shown at bottom with red color indicating high wind speed.
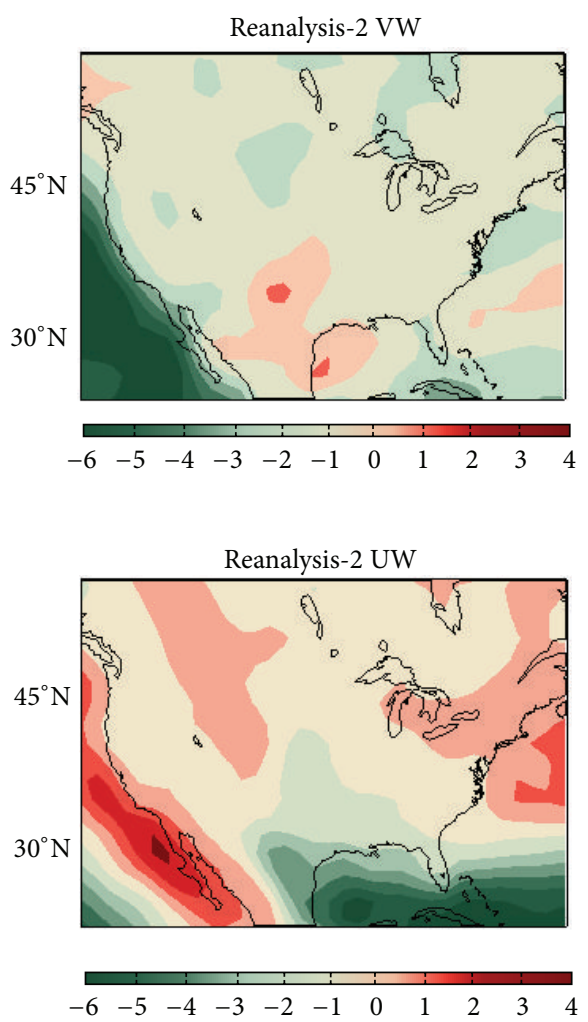
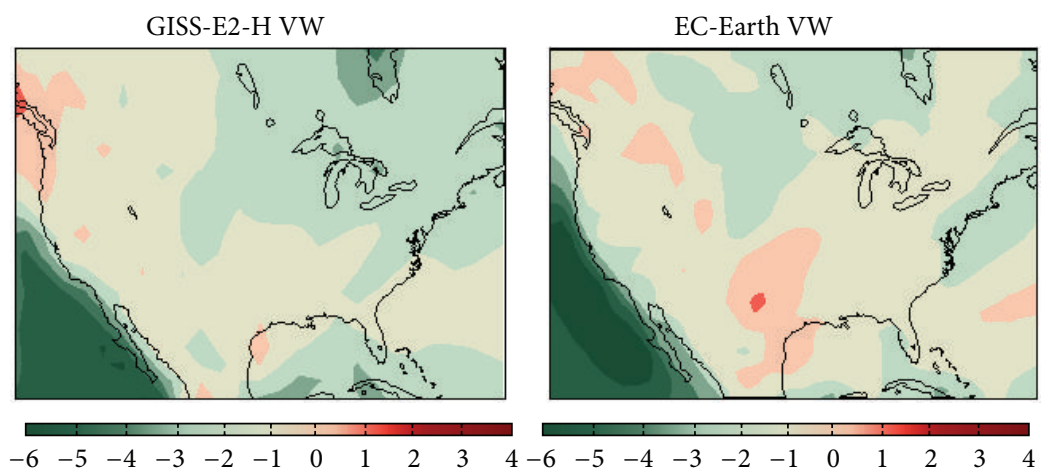

(a)
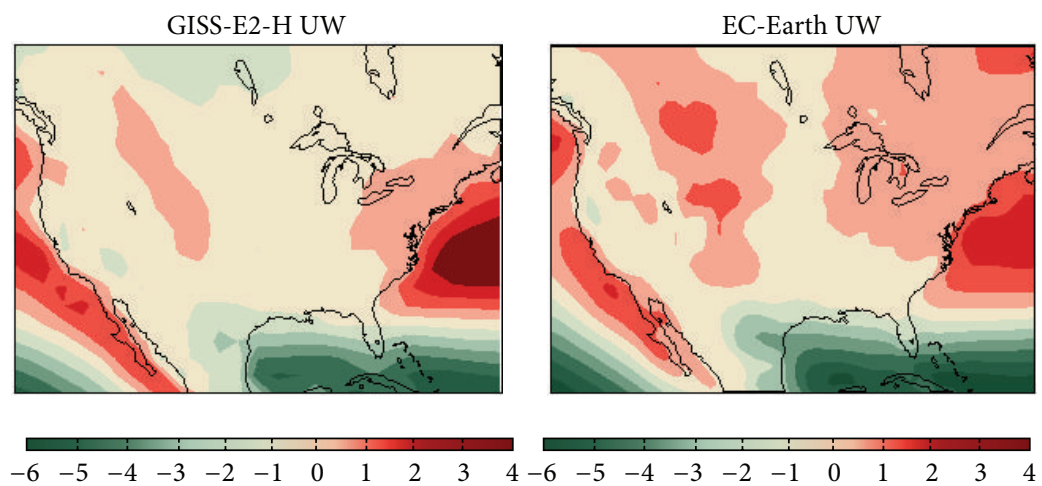

(b)

FIGURE 5: A comparison of the 1979-1999 climatology of the $v$-component (a) and $u$-component (b) of the $10 \mathrm{~m}$ wind over North America from reanalysis-2 (left), GISS-E2_H historical run (middle) and EC-Earth historical run (right). The color scale, in $\mathrm{m} / \mathrm{s}$, is shown at bottom. Red and green indicate positive and negative velocities.

winter. While significant changes in the wind direction are found in a few isolated places, for example, Illinois in the top row of Figure 6, and Pennsylvania and off the coast of New Jersey in the bottom row of Figure 6, for most regions shown in Figures 6 and 7 the GHG forcing does not induce major changes in the wind direction and the patterns of surface wind.

\section{Discussions}

Our analysis has used the wind speed and horizontal velocity field at 10-meter height that are directly available from the CMIP5 archive. It is understood that the $10 \mathrm{~m}$ wind is used as a proxy of the wind at the turbine height of $80-100 \mathrm{~m}$, which is typically stronger than the wind at near surface. Given so, 
Historical JJA-Central USA
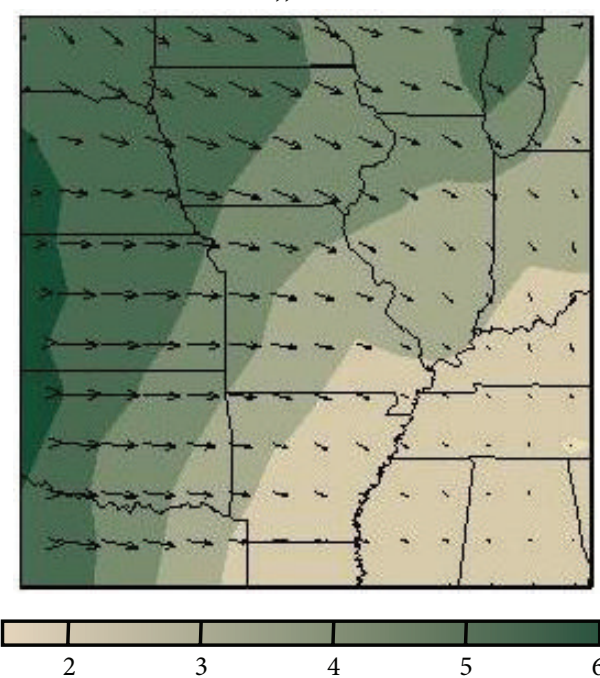

Historical JJA-East Coast

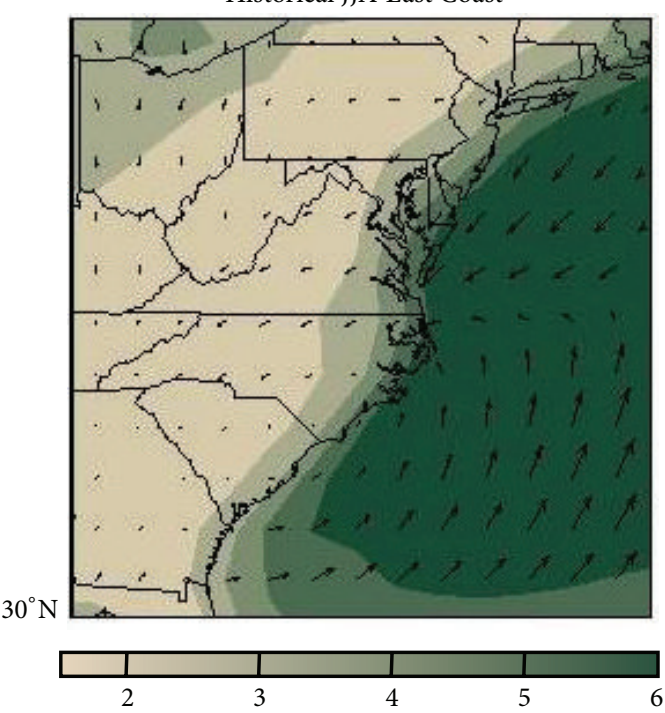

(a)

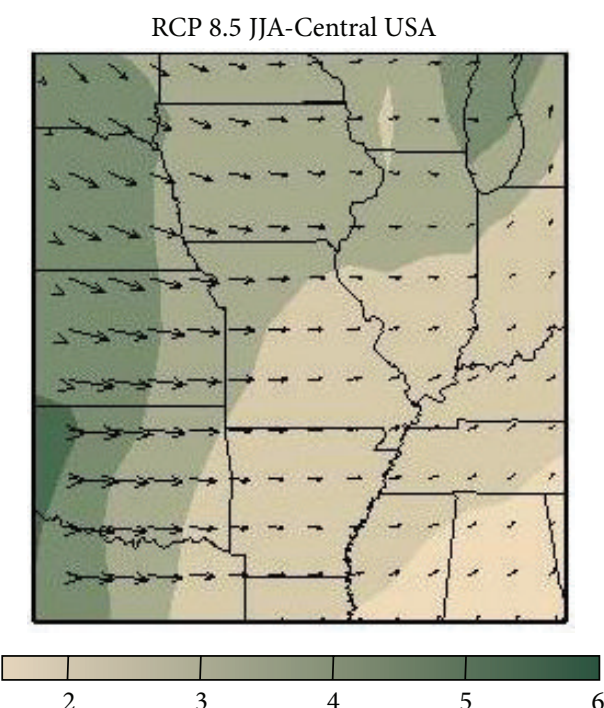

RCP 8.5 JJA-East Coast

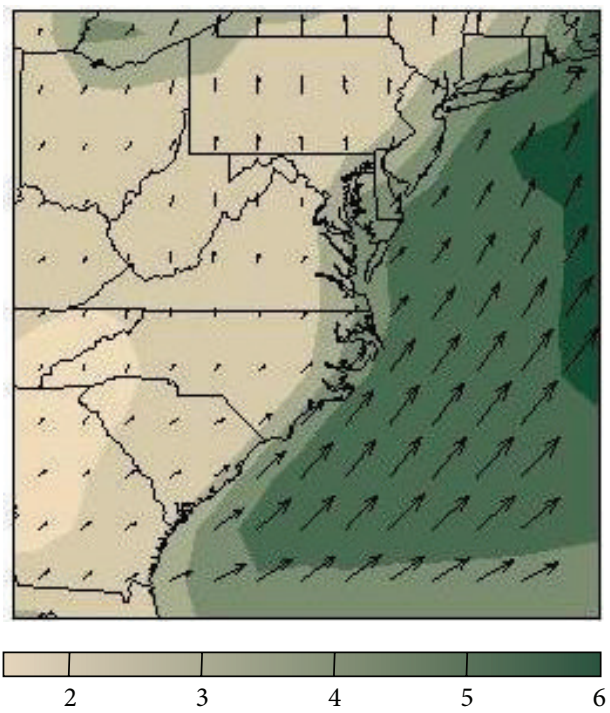

(b)

FIGURE 6: Detailed maps of the $10 \mathrm{~m}$ velocity fields for selected regions from the EC-Earth model simulations in CMIP5. (a) shows the 20th century historical runs and (b) the 21st century RCP 8.5 runs. Both are the average over the last two decades of the respective runs, and over summer (JJA) only. Top: Central United States. Bottom: the East Coast of the United States. The arrows indicate the climatological wind field and the color shading indicates the magnitude of the wind vectors shown. The color scale for the latter, in $\mathrm{m} / \mathrm{s}$, is shown at the bottom.

a more useful measure of the influence of the GHG forcing is perhaps the percentage change, instead of the absolute value of the change, in the $10 \mathrm{~m}$ wind speed. At a grid point ( $i$, $j$ ), where $i$ and $j$ are the indices for longitude and latitude, the multimodel average of the percentage change in the $10 \mathrm{~m}$ wind speed is defined as

$$
\mu_{i, j}=\frac{1}{5} \sum_{k=1}^{5} \frac{(\mathrm{WS} 21)_{k, i, j}-(\mathrm{WS} 20)_{k, i, j}}{(\mathrm{WS} 20)_{k, i, j}}
$$

where WS21 is the wind speed from the RCP 8.5 runs and WS20 is the wind speed from the historical runs and $k$ is the index for the model. Since the five models have different horizontal resolutions, the CMIP5 data were first interpolated onto the same grid (using that of the reanalysis-2) before the statistics were calculated. The calculation of $\mu_{i, j}$ would not be meaningful over the regions where the surface wind speed (WS20) is very small, where wind turbines are also less likely to be built. To exclude those regions, we consider that most of the high capacity wind turbines operate above $5 \mathrm{~m} / \mathrm{s}$ for practical energy production. By Hellman exponent and wind gradient equation used for wind turbines (e.g., Kaltschmitt et al. [14]), the wind speed at $80 \mathrm{~m}$ is typically 1.5 to 2 times that of the wind speed at $10 \mathrm{~m}$ height. Thus, we will neglect the regions with the $10 \mathrm{~m}$ wind speed less than $2 \mathrm{~m} / \mathrm{s}$. (If at least one model meets this criterion at a given grid point, that 

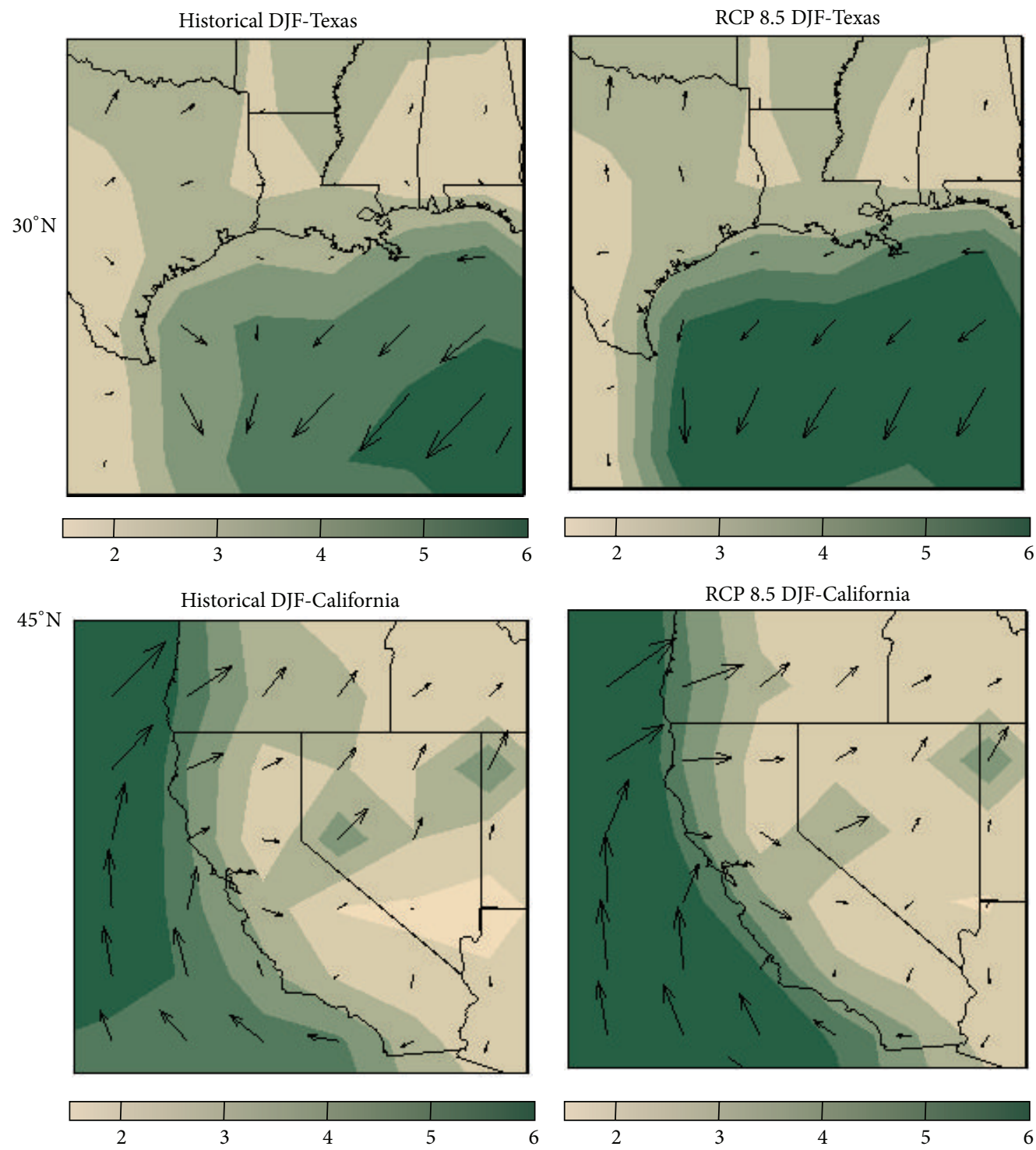

(a)

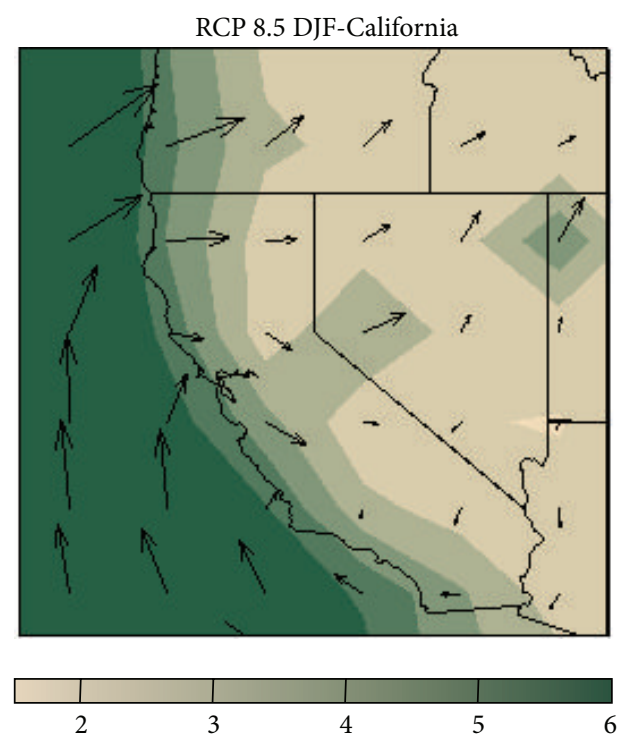

(b)

FIgURE 7: Similar to Figure 6 but for the surface wind fields from GISS-E2-H simulations for winter (DJF) and for two different regions. (a) and (b) are the historical and RCP 8.5 runs, respectively. Top: The Southern USA and part of Gulf of Mexico. Bottom: West Coast of the USA and off shore of California.

grid point is excluded from the calculation of $\mu_{i, j}$.) The maps of $\mu_{i, j}$ are shown for winter in Figure 8(a) and for summer in Figure $8(\mathrm{~b})$. The white areas in Figure 8 are where either the climatology of the surface wind is small or the percentage change of the surface wind is small. The intramodel standard deviation (as a measure of the deviation from the multimodel mean, $\mu_{i, j}$ ) of the percentage change for the two seasons is also shown in Figure 9. The standard deviation is calculated only where the mean is calculated. For the convenience of plotting the result, in Figure 9, the standard deviation is set to zero over the areas where it is not calculated. In winter when the climatological surface wind is stronger overall, we find a moderate increase of $5-10 \%$ of the near surface wind speed over the Central and North-Central USA and the coastal regions in California and along the South and East Coasts of the USA. Using Betz's law (wind power proportional to the cube of wind speed), the equivalent changes in wind power potential would be approximately $15-30 \%$ per century over the colored areas in Figure 8(a). In summer, a decrease in wind speed at a similar range of $5-10 \%$ is found over the aforementioned coastal regions. A greater decrease, close to $20 \%$, is found over isolated locations in West and WestCentral USA. Nevertheless, those values are less reliable since they are associated with high intramodel standard deviation (compare the Figures 8(a) and 9(a)), indicating that the higher percentage of change is contributed by one or a small number of outliers.

In the preceding analysis we converted the GHG-induced change in the $10 \mathrm{~m}$ wind speed to an estimate of the change in wind power potential by simply applying the cubic law to 


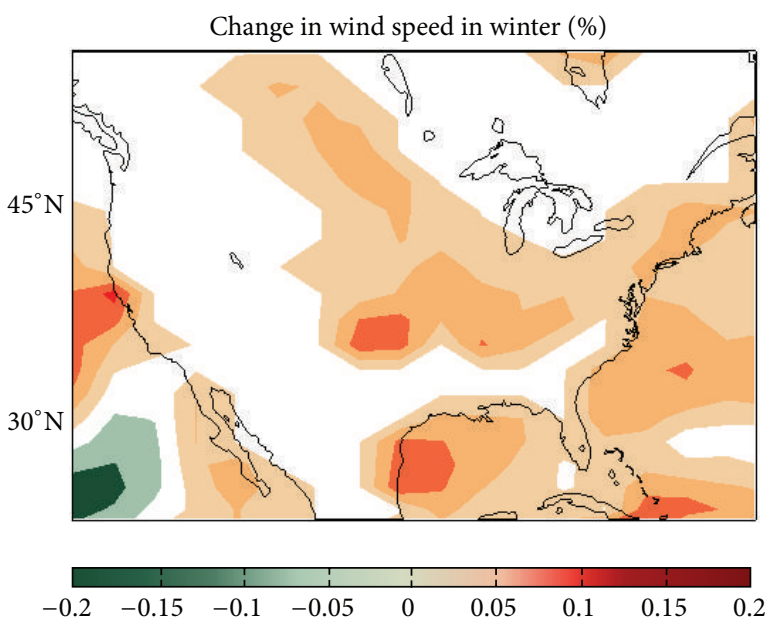

(a)

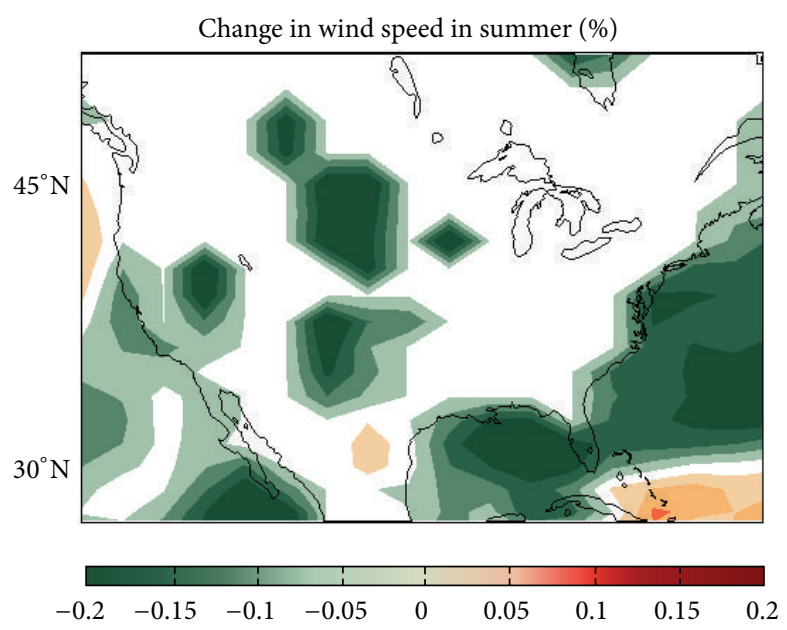

(b)

FiguRE 8: The multimodel mean of the percentage change in surface wind speed over North America for winter (a) and summer (b). See text for definition. Red indicates an increase and green indicates a decrease in wind speed. The values range from $-20 \%$ to $20 \%$, as indicated by the color scale at the bottom.

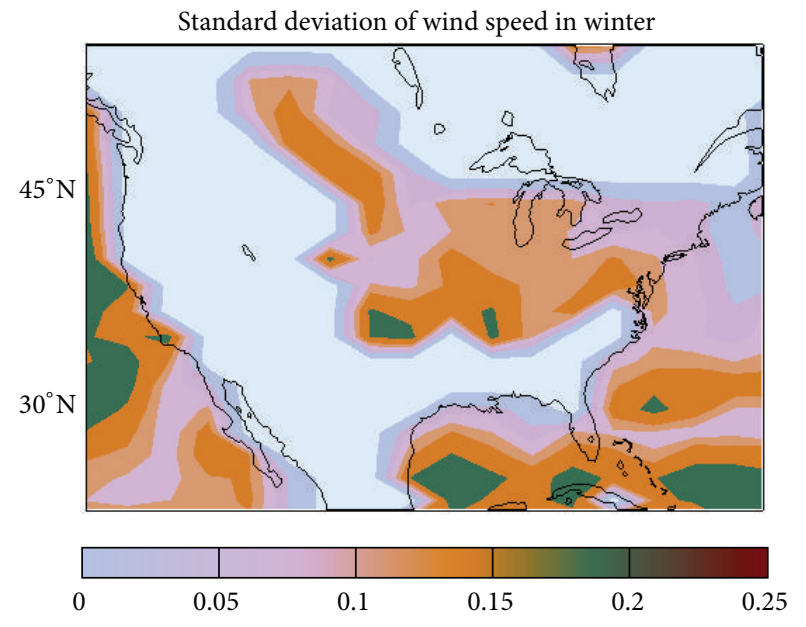

(a)

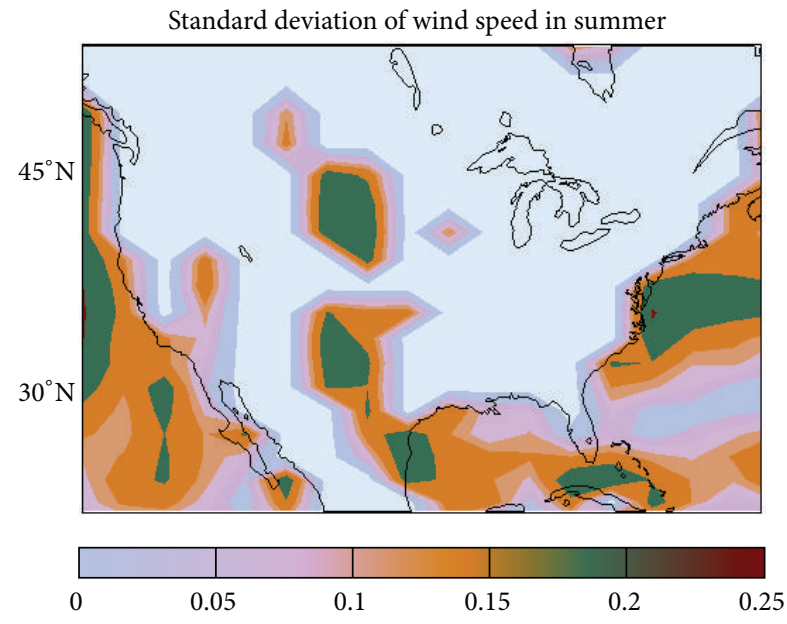

(b)

FIGURE 9: The intramodel standard deviation, with respect to the mean, as shown in Figure 8, of the percentage change in surface wind speed. (a) and (b) are for winter and summer, respectively. Where the standard deviation is not calculated (see text), it is set to zero and colored in gray. The color scale is shown at bottom.

the wind speed in the 20th and 21st century, then calculating the percentage change in "wind speed cubed." We used this simple approach because the CMIP5 archive does not provide the detailed wind and temperature profiles in the lower boundary layer. (Air temperature is available at $2 \mathrm{~m}$ only.) Note that the wind speed at the turbine height, $U$, is approximately related to the wind speed at a reference height (10 $\mathrm{m}$ in our case), $U_{R}$, by the relation of $\left(U / U_{R}\right)=$ $\left(Z / Z_{R}\right)^{\alpha}$, where $Z$ and $Z_{R}$ are the heights of the turbine and the reference level and $\alpha(\sim 0.14$ for a neutrally stable profile) is an adjustable parameter (e.g., Peterson and Hennessey Jr. [16]). Thus, we obtained the estimate of the percentage change in wind power potential by implicitly assuming that $\alpha$, or the static stability profile in the lower boundary layer, is not changed by the GHG forcing in the future. A validation of this assumption is beyond the scope of this study but will be a useful future work for climate modeling with high vertical resolutions.

Our results of the changes in surface wind speed and wind direction suggest that the GHG forcing (as used in CMIP5 simulations under the RCP 8.5 scenario) has a moderate, but not major, influence on the near-surface wind fields over North America. This broadly agrees with the conclusion of Pryor and Barthelmie [8] that the estimate of wind power potential over the USA using present-day climatology will remain useful in the coming decades. Note that the trend considered in this study is defined as the centennial change over the whole 21 st century. The equivalent change over only 
the next 50 years (as discussed by Pryor and Barthelmie [8]) would be smaller. The RCP 8.5 scenario chosen for our analysis is among the ones with a higher estimate of future GHG emissions. If the RCP 4.5 scenario was chosen, the projected trend would also be smaller.

\section{Concluding Remarks}

Using 5 models from the CMIP5 archive and comparing the RCP 8.5 runs with historical runs, moderate centennial trends in the $10 \mathrm{~m}$ wind speed are projected over North America. In winter, we found 5-10 percent increases per century over Central and East-Central United States, the Californian Coast, and the South and East Coasts of the USA. In summer, decreases in the wind speed ranging from 5 to 10 percent per century are found over the same coastal regions. These projected changes in the surface wind speed are moderate overall. From the global model projections, the estimate of wind power potential for North America based on present-day climatology will remain accurate in the coming decades. The relatively coarse resolutions of the global models do not allow an accurate representation of the mesoscale and submesoscale topography, which might affect the projections of the changes in the surface wind field. Our results will serve as a useful basis to guide future work on downscaling the CMIP5 model outputs to the submesoscale, which may help resolve the topographic effects. The RCP scenarios used in CMIP5 do not consider the effects of future land-use changes, including those related to the construction of large-scale wind farms. An integration of those effects into regional climate modeling, using the CMIP5 global model outputs as the boundary conditions, will help refine the conclusions of this work.

\section{Conflict of Interests}

The authors declare that there is no conflict of interests regarding the publication of this paper.

\section{References}

[1] A. Lopez, B. D. Roberts, N. Heimiller, N. Blair, and G. Porro, "U.S Renewable Energy Technical Potential: A GIS based analysis," Tech. Rep. NREL/TP-6A20-51946, National Renewable Energy Laboratory, Golden, Colo, USA, 2012.

[2] J. M. Freedman, K. T. Waight, and P. B. Duffy, "Does climate change threaten wind resources?" North American Wind Power, vol. 6, pp. 49-53, 2009.

[3] D. Ren, "Effects of global warming on wind energy availability," Journal of Renewable and Sustainable Energy, vol. 2, no. 5, Article ID 052301, 2010.

[4] K. E. Taylor, R. J. Stouffer, and G. A. Meehl, "An overview of CMIP5 and the experiment design," Bulletin of the American Meteorological Society, vol. 93, no. 4, pp. 485-498, 2012.

[5] IPCC, Climate Change 2013: The Physical Science Basis, Working Group I Contribution to Fifth Assessment Report of Intergovernmental Panel on Climate Change, Cambridge University Press, Cambridge, UK, 2013.
[6] R. Seager, M. Ting, I. Held et al., "Model projections of an imminent transition to a more arid climate in southwestern North America," Science, vol. 316, no. 5828, pp. 1181-1184, 2007.

[7] N. C. Baker and H.-P. Huang, "A comparative study of precipitation and evaporation in semiarid regions between the CMIP3 and CMIP5 climate model ensembles," Journal of Climate, vol. 27, no. 10, pp. 3731-3749, 2014.

[8] S. C. Pryor and R. J. Barthelmie, "Assessing climate change impacts on the near-term stability of the wind energy resource over the United States," Proceedings of the National Academy of Sciences of the United States of America, vol. 108, no. 20, pp. 81678171, 2011.

[9] L. O. Mearns, R. Arritt, S. Biner et al., "The North American regional climate change assessment program: overview of phase I results," Bulletin of the American Meteorological Society, vol. 93, no. 9, pp. 1337-1362, 2012.

[10] G. A. Meehl, C. Covey, T. Delworth et al., "The WCRP CMIP3 multimodel dataset: a new era in climatic change research," Bulletin of the American Meteorological Society, vol. 88, no. 9, pp. 1383-1394, 2007.

[11] D. W. Keith, J. F. DeCarolis, D. C. Denkenberger et al., "The influence of large-scale wind power on global climate," Proceedings of the National Academy of Sciences of the United States of America, vol. 101, no. 46, pp. 16115-16120, 2004.

[12] A. S. Adams and D. W. Keith, "Are global wind power resource estimates overstated?" Environmental Research Letters, vol. 8, Article ID 015021, 2013.

[13] H. Paek and H.-P. Huang, "Centennial trend and decadal-tointerdecadal variability of atmospheric angular momentum in CMIP3 and CMIP5 simulations," Journal of Climate, vol. 26, no. 11, pp. 3846-3864, 2013.

[14] M. Kaltschmitt, W. Streicher, and A. Wiese, Renewable Energy: Technology, Econom Ics, and Environment, Springer, New York, NY, USA, 2007.

[15] M. Kanamitsu, W. Ebisuzaki, J. Woollen et al., "NCEP-DOE AMIP-II reanalysis (R-2)," Bulletin of the American Meteorological Society, vol. 83, no. 11, pp. 1631-1559, 2002.

[16] E. W. Peterson and J. P. Hennessey Jr., "On the use of power laws for estimates of wind power potential," Journal of Applied Meteorology, vol. 17, no. 3, pp. 390-394, 1978. 

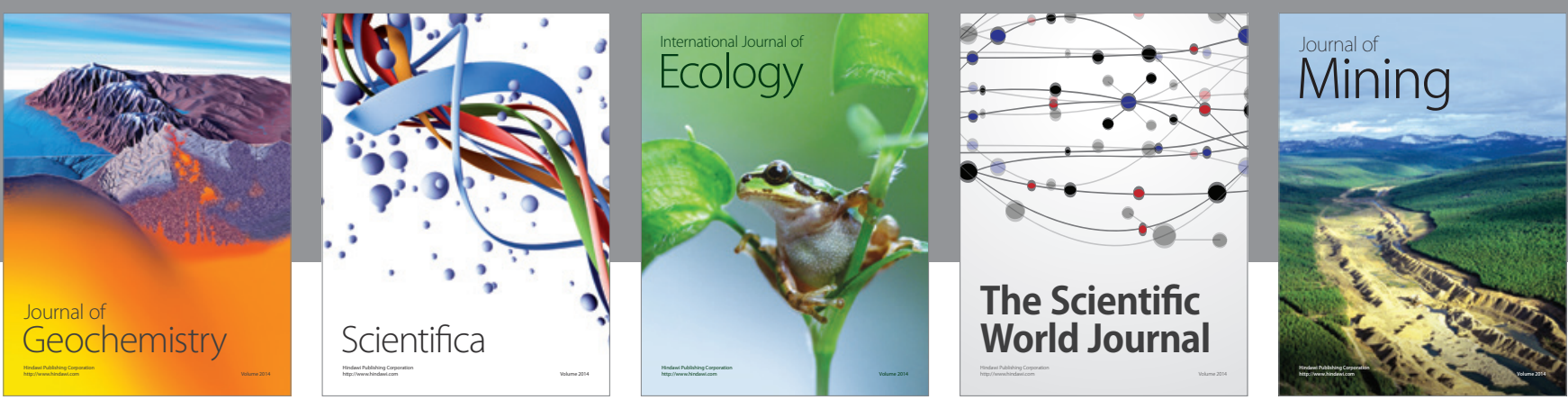

The Scientific World Journal
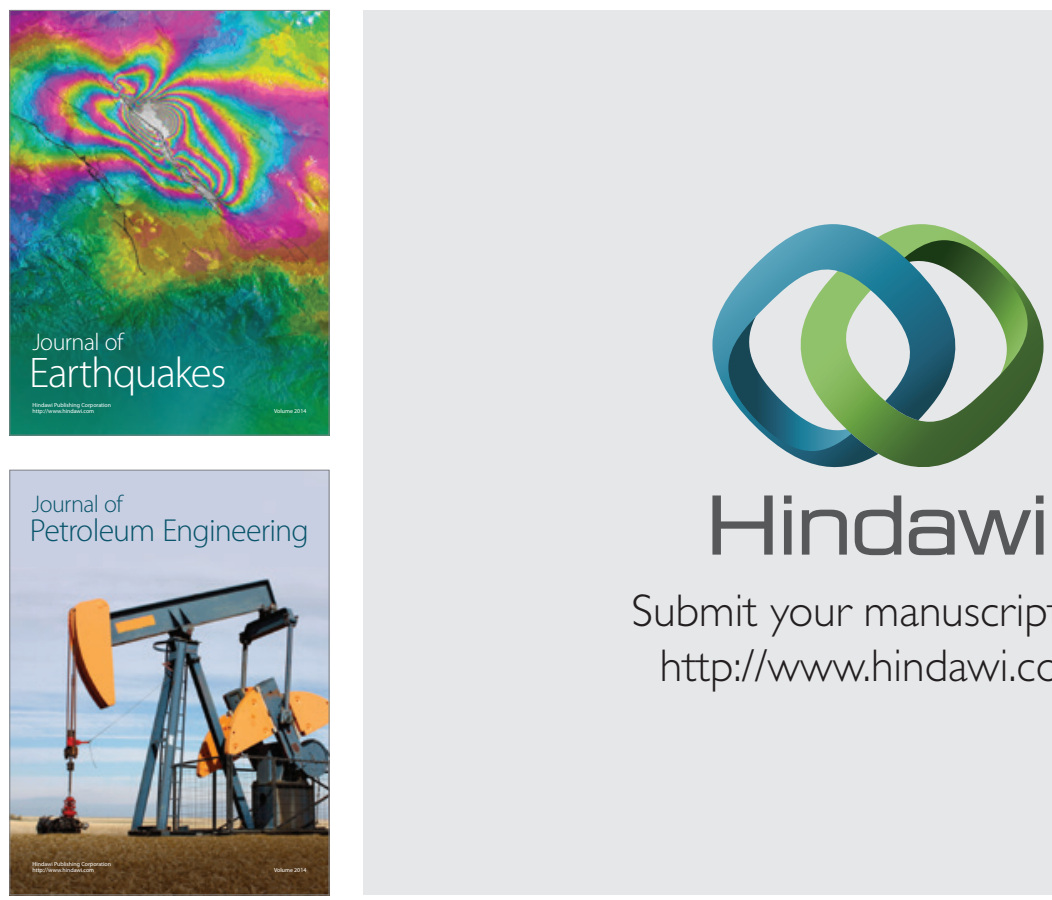

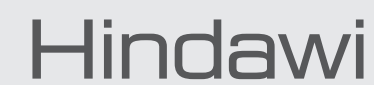

Submit your manuscripts at

http://www.hindawi.com
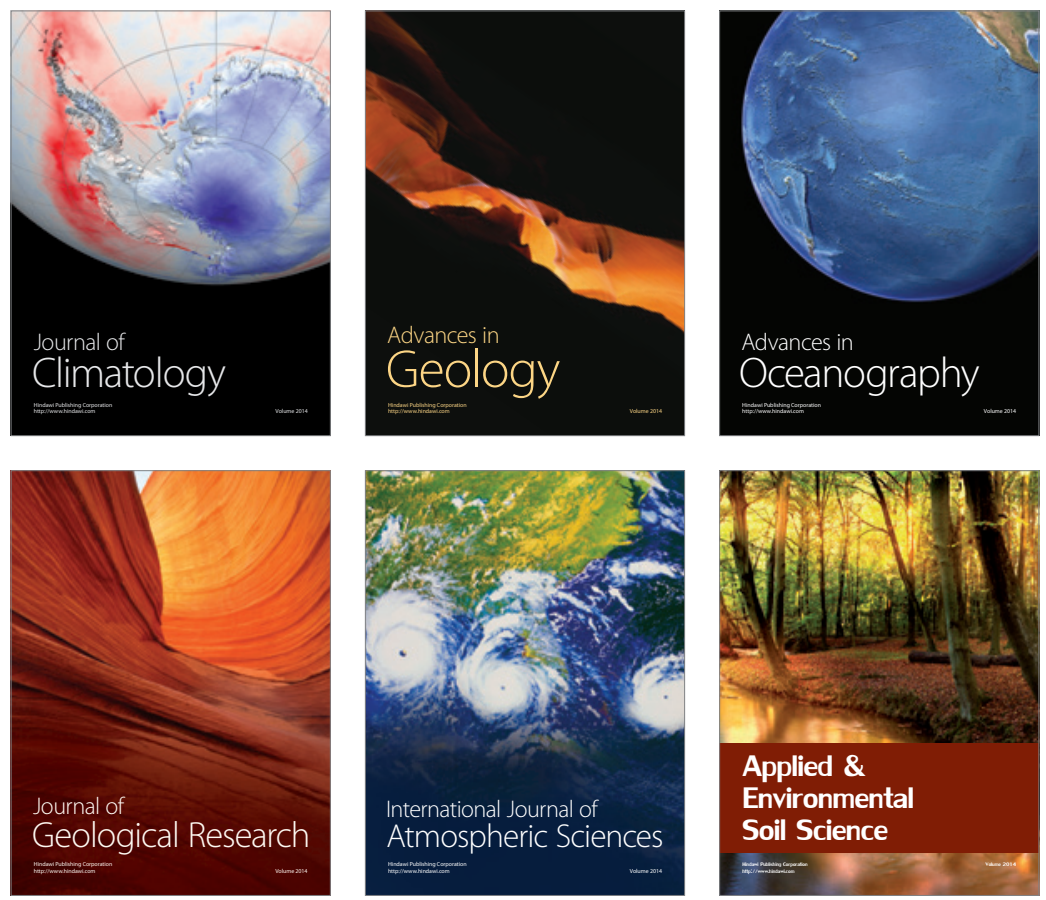
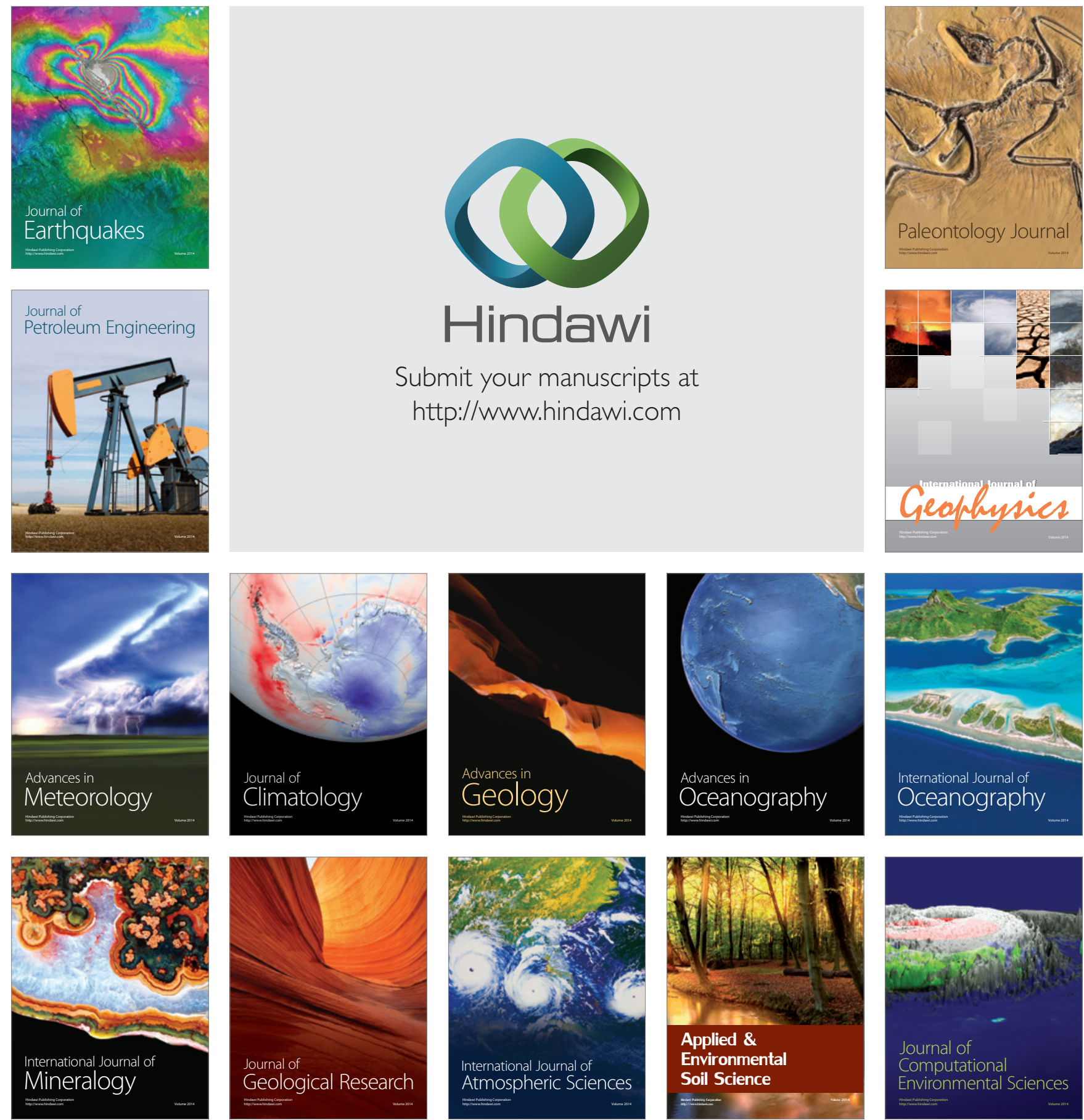